\title{
Plantas de cobertura e seus efeitos sobre o feijoeiro em plantio direto(1)
}

\author{
Tadário Kamel de Oliveira(2), Gabriel José de Carvalho(2) e Raimundo Nonato de Souza Moraes ${ }^{(2)}$
}

Resumo - O objetivo deste trabalho foi estimar o rendimento de matéria fresca, matéria seca e o acúmulo de nutrientes da fitomassa produzida por milheto (Pennisetum americanum (L.) Leek), sorgo (Sorghum bicolor (L.) Moench), milho (Zea mays L.), mucuna-preta (Stizolobium aterrimum) e feijãode-porco (Canavalia ensiformis (L.) DC.), em cultivo exclusivo e consorciado, e seus efeitos sobre o feijoeiro (Phaseolus vulgaris L. cv. Carioca) em plantio direto. Os tratamentos consistiram no cultivo exclusivo das espécies e nos consórcios das gramíneas com as leguminosas. Utilizou-se o delineamento experimental em blocos casualizados, com quatro repetições. O sorgo em cultivo exclusivo apresenta maior produtividade de matéria fresca e, juntamente com o milheto exclusivo e o consórcio milheto e mucuna-preta, maior produtividade de matéria seca. Ocorre maior acúmulo de nutrientes no milheto exclusivo e consorciado com mucuna-preta. Posteriormente, realizou-se o plantio direto do feijoeiro, cujo rendimento de grãos é influenciado pelas diferentes palhadas das plantas de cobertura no sistema plantio direto, sendo mais afetado pela espécie produtora de palha do que pela sua forma de cultivo.

Termos para indexação: Phaseolus vulgaris, cultivo consorciado, matéria seca, fitomassa, grão, rendimento.

\section{Cover crops and their effects on bean plant in no-tillage system}

\begin{abstract}
The objective of this study was to estimate the production of fresh matter, dry matter and the accumulation of nutrients of the phytomass produced by millet (Pennisetum americanum (L.) Leek Perl millet), sorghum (Sorghum bicolor (L.) Moench), corn (Zea mays L.), black velvet bean (Stizolobium aterrimum) and jack beans (Canavalia ensiformis (L.) DC.) in single and associated cultivation and their effects on bean plants (Phaseolus vulgaris L.) in no-tillage system. Treatments consisted of species in isolated cultivation and the association of gramineous and leguminous plants. The experimental design was that of randomized blocks, with four repetitions. The sorghum in an isolated cultivation shows major productivity of fresh matter. Sorghum and millet in isolated cultivation and the association of millet with black velvet bean produce a great amount of dry matter. The greatest accumulation of nutrients by millet occurs in isolated cultivation and in association with black velvet bean. In the direct bean planting carried out on the straw produced by cover crops, it was verified that the culture yield is more influenced by producer species of straw than by the kind of their cultivation.
\end{abstract}

Index terms: Phaseolus vulgaris, mixed cropping, dry matter, phytomass, grain, yield.

\section{Introdução}

A definição de espécies com elevada produtividade de fitomassa para cobertura do solo é um dos fatores de sucesso do sistema de plantio direto. No entanto, a produção de palhada para plantio di-

\footnotetext{
(1) Aceito para publicação em 25 de janeiro de 2002.

(2) Universidade Federal de Lavras, Dep. de Agricultura, Caixa Postal 37, CEP 37200-000 Lavras, MG. E-mail: tadario@ufla.br,gab@ufla.br, rmoraes@ufla.br
}

reto no cerrado brasileiro está sujeita às condições de umidade e temperatura elevadas em boa parte do ano, que causam a rápida decomposição da fitomassa depositada sobre o solo. Por esta razão, resíduos com maior relação $\mathrm{C} / \mathrm{N}$ (carbono/nitrogênio), como os de culturas comerciais, ou de plantas de cobertura, deverão ser mais utilizados em plantio direto, pois quanto maior essa relação, mais lenta a decomposição dos resíduos (Calegari et al., 1993).

Espécies utilizadas como adubo verde, principalmente leguminosas, apesar de possuírem menor relação $\mathrm{C} / \mathrm{N}$, também podem ser incluídas no plano de 
rotação de culturas em sistema de plantio direto, pois apresentam vantagens a curto prazo, como a liberação de nutrientes durante a decomposição (Darolt, 1998).

Por meio do consórcio de leguminosas e gramíneas com elevada produção de matéria seca, podem-se conciliar proteção e adubação do solo. Dentre as espécies passíveis de serem consorciadas, Alcântara \& Bufarah (1988) citam que milheto e sorgo podem ser consorciados com leguminosas, como kudzu-tropical, lab-lab, caupi ou mucuna, e Calegari (1995) recomenda o feijão-de-porco e a mucuna-preta em consórcio com a cultura do milho.

Em diversas regiões do Brasil está iniciando-se a adoção do sistema de plantio direto, porém é pouco o conhecimento sobre plantas de cobertura que possam produzir quantidade de matéria seca suficiente para o sistema, e, conseqüentemente, manter ou elevar a fertilidade do solo e a produtividade das culturas comerciais. Portanto, há necessidade de se conhecer o modo correto de aplicação desse sistema, em relação ao cultivo de gramíneas e leguminosas como plantas de cobertura do solo.

O objetivo deste trabalho foi estimar o rendimento de matéria fresca, matéria seca e o acúmulo de nutrientes da fitomassa produzida por gramíneas e leguminosas em cultivo exclusivo e consorciado, e seus efeitos sobre o feijoeiro em plantio direto.

\section{Material e Métodos}

O trabalho foi realizado em duas fases, na área experimental do Departamento de Agricultura da Universidade Federal de Lavras, Lavras, MG, no ano agrícola 1999/2000. A área encontrava-se em pousio, sobre solo Podzólico Vermelho-Amarelo distrófico, textura média, cuja análise química e granulométrica $(0-20 \mathrm{~cm})$ revelou os seguintes resultados: $\mathrm{pH}$ em água, 5,$3 ; \mathrm{P}, 1,67 \mathrm{mg} / \mathrm{dm}^{3} ; \mathrm{K}, 49,3 \mathrm{mg} / \mathrm{dm}^{3}$; $\mathrm{Ca}, 1,03 \mathrm{cmol}_{\mathrm{C}} / \mathrm{dm}^{3} ; \mathrm{Mg}, 0,5 \mathrm{cmol}_{\mathrm{C}} / \mathrm{dm}^{3} ; \mathrm{Al}, 0,33 \mathrm{cmol}_{\mathrm{d}} / \mathrm{dm}^{3}$; $\mathrm{H}+\mathrm{Al}, 3,76 \mathrm{cmol}_{\mathcal{C}} / \mathrm{dm}^{3}$; soma de bases $(\mathrm{S}), 1,67 \mathrm{cmol}_{\mathrm{d}} / \mathrm{dm}^{3}$; CTC efetiva (t), 2,0 $\mathrm{cmol}_{\mathrm{c}} / \mathrm{dm}^{3}$; CTC potencial (T), $5,43 \mathrm{cmol}_{\mathrm{c}} / \mathrm{dm}^{3}$; saturação de alumínio (m), 15,5\%; saturação de bases (V), 30,8\%; MO, $18 \mathrm{~g} / \mathrm{kg}$; areia, $513 \mathrm{~g} / \mathrm{kg}$; silte, $150 \mathrm{~g} / \mathrm{kg}$ e argila, $337 \mathrm{~g} / \mathrm{kg}$. O clima da região, segundo a classificação de Köppen, é do tipo Cwa com transição para Cwb (Vianello \& Alves, 1991). As variações climáticas ocorridas no período experimental foram, em média, $1.000,8 \mathrm{~mm}$ e $115,7 \mathrm{~mm}$ de precipitação total, $28^{\circ} \mathrm{Ce} 26,4^{\circ} \mathrm{C}$ de temperatura máxima do ar, $17,5^{\circ} \mathrm{C}$ e $14,1^{\circ} \mathrm{C}$ de temperatura mínima do ar e 75,9\% e 71,3\% de umidade relativa do ar, durante a primeira e segunda fases, respectivamente.

$\mathrm{Na}$ primeira fase foi realizado um experimento com milheto, sorgo, milho, mucuna-preta e feijão-de-porco, em cultivo exclusivo e consorciado. O delineamento experimental utilizado foi o de blocos casualizados com quatro repetições. Os tratamentos, num total de 11 , constituíram-se do cultivo exclusivo das espécies e dos consórcios das gramíneas com as leguminosas. A área de cada parcela era de $15 \mathrm{~m}^{2}$ ( 3 x $\left.5 \mathrm{~m}\right)$, com bordaduras laterais de $1,0 \mathrm{me}$ bordadura de cabeceira de $0,50 \mathrm{~m}$, delimitando a área útil da parcela.

Inicialmente, fez-se o corte da vegetação da área com roçadora de tração mecânica. A análise química do solo revelou a necessidade de aplicação de calcário e P. Com a finalidade de incorporar os $2.400 \mathrm{~kg} / \mathrm{ha}$ de calcário dolomítico (PRNT 100\%) e eliminar a camada compactada $(10-20 \mathrm{~cm})$, realizou-se uma aração seguida de gradagem, 60 dias antes do plantio. Foram aplicados a lanço, $1.750 \mathrm{~kg} / \mathrm{ha}$ de superfosfato simples (Comissão de Fertilidade do Solo do Estado de Minas Gerais, 1989), que foram incorporados com nova gradagem, antes do plantio. Em seguida, foram abertos sulcos de plantio com cultivador de tração animal, e procedeu-se ao plantio manual das gramíneas, em novembro de 1999. Por ocasião do plantio, aplicaram-se, manualmente, $300 \mathrm{~kg} / \mathrm{ha}$ da fórmula 4-30-16. O milho (cultivar DINA 170) foi cultivado na densidade de 5 plantas $/ \mathrm{m} \mathrm{e}$ com espaçamento de $0,80 \mathrm{~m}$ entre linhas, adotando-se o mesmo espaçamento para o sorgo (cultivar AG 2002), na densidade de 12 a 15 plantas $/ \mathrm{m}$, tanto no cultivo exclusivo quanto em consórcio. $\mathrm{O}$ milheto (variedade comum) foi semeado na densidade de 40 a 50 sementes $/ \mathrm{m}$, utilizandose $0,25 \mathrm{~m}$ entre linhas nas parcelas de cultivo exclusivo e o mesmo espaçamento do milho e sorgo nas parcelas de consórcio. A semeadura das leguminosas foi realizada 25 dias após a das gramíneas, nas entrelinhas de plantio, quando estas já estavam estabelecidas. Não foi realizada adubação de plantio nem inoculação nas sementes das leguminosas. Utilizou-se de 5 a 8 sementes/m e o espaçamento de $0,50 \mathrm{~m}$ entre linhas para o cultivo exclusivo.

O manejo das espécies deu-se no ponto de colheita do milho verde (100 dias após o plantio das gramíneas). As plantas de cobertura de cada parcela foram cortadas rente ao solo, e pesadas, para determinação do rendimento de matéria fresca, transformando-se os valores em t/ha, conforme o espaçamento de cada espécie e forma de cultivo. Das plantas cortadas de cada parcela foi retirada uma amostra que foi pesada, e colocada em estufa com ventilação forçada a $65^{\circ} \mathrm{C}$, até atingir peso constante. A porcentagem de matéria seca em cada amostra correspondia ao 
teor de matéria seca, que, multiplicado pela produção de matéria fresca da parcela, forneceu a produtividade de matéria seca. As amostras de cada parcela após a secagem em estufa foram moídas em moinho tipo Willey, para determinação dos teores de macro e micronutrientes. $\mathrm{O}$ acúmulo de macro e micronutrientes foi obtido pelo produto da quantidade de matéria seca com o teor dos nutrientes da parte aérea das plantas de cobertura.

A segunda fase do trabalho consistiu no plantio direto do feijoeiro sobre as palhadas produzidas nos tratamentos da fase anterior. $\mathrm{O}$ delineamento experimental foi o mesmo da primeira fase; cada parcela experimental foi constituída por nove linhas de feijoeiro com 3,0 m de comprimento. Nas três linhas centrais avaliaram-se as variáveis de produção e altura de plantas. Além das linhas de bordadura, a área útil de cada parcela correspondia a duas linhas para amostragem destrutiva, visando avaliar o peso de matéria seca da parte aérea, na fase de floração. Em março de 2000 foi realizado o plantio direto do feijão (cultivar Carioca), utilizando-se semeadora/adubadora de tração mecânica. Por ocasião do plantio aplicaram-se $500 \mathrm{~kg} / \mathrm{ha}$ da fórmula 4-14-8. O espaçamento adotado foi de $0,45 \mathrm{~m}$ entre linhas, com 12 sementes/m.

A colheita foi realizada 90 dias após o plantio, e as seguintes características foram avaliadas: estande final, altura de plantas, peso de matéria seca da parte aérea, número de vagens por planta, número de grãos por vagem e peso médio de 100 grãos, determinado pela estimativa do peso médio de três amostras de 100 grãos por parcela. Tanto nas amostras de 100 grãos como no rendimento de grãos ( $\mathrm{kg} / \mathrm{ha}$ ), o peso foi corrigido para $13 \%$ de umidade, conforme Associação Brasileira de Educação Agrícola Superior (1987):

$\mathrm{Pf}=[\mathrm{Pi}(100-\mathrm{Ui})] /(100-\mathrm{Uf})$,

em que Pf é o peso corrigido; Pi, o peso inicial dos grãos colhidos; Ui, a umidade inicial por ocasião da pesagem; Uf, a umidade final requerida para correção.

Os dados obtidos foram submetidos ao teste de homogeneidade de variância (F máximo) (Banzatto \& Kronka, 1995; Ferreira, P., 1996), sendo transformados quando as variáveis não encontravam-se homogêneas. Os dados de produtividade de matéria seca, acúmulos de N, P, K, S e Mn foram transformados em $x^{0,5}$, e o teor de matéria seca e os conteúdos acumulados de $\mathrm{Ca}, \mathrm{Mg}, \mathrm{B}$, e Fe foram transformados em $\log \mathrm{x}$. Realizou-se análise de variância, aplicando-se às médias de tratamentos o teste de Tukey, a $5 \%$ de probabilidade.

\section{Resultados e Discussão}

Na primeira fase do trabalho, houve diferença significativa entre os cultivos exclusivos e consorcia- dos em todas as variáveis analisadas (Tabela 1). A maior produção de matéria fresca (MF) foi obtida pelo sorgo em cultivo exclusivo, diferindo significativamente das demais espécies, as quais foram estatisticamente iguais, exceto a mucuna-preta e o feijãode-porco em cultivo exclusivo, que apresentaram as menores produções.

De modo geral, as produtividades encontram-se inseridas ou superam os limites citados por Alcântara \& Bufarah (1988), ou seja, 35 a 55 t/ha de MF de milheto e 60 a 70 t/ha de MF de sorgo, o que confirma o alto potencial de produção de matéria fresca dessas espécies. Os resultados obtidos também são superiores aos citados por Balbino et al. (1996).

A produtividade de matéria fresca do feijão-deporco não atingiu os limites de 14 e 30 t/ha, estabelecidos por Calegari (1995). No entanto, foi semelhante aos resultados encontrados por Ferreira, A. (1996). A produtividade de matéria fresca da mucuna-preta em cultivo exclusivo também não atingiu os limites de 10 a 40 t/ha, citados por Alcântara \& Bufarah (1988) e por Calegari (1995).

De maneira geral, a baixa produtividade de matéria fresca das leguminosas pode ser explicada pelo fato de não terem sido realizadas adubações ou inoculação das sementes, e, especialmente, em relação à mucuna-preta, que sofreu ataque intenso de formigas cortadeiras, desde a germinação.

Quanto à produção de matéria seca (MS), o consórcio milheto e mucuna-preta apresentou a maior produtividade, embora não diferindo das gramíneas em cultivo exclusivo e da maioria dos consórcios (Tabela 1).

A média geral de produtividade de matéria seca foi 10,02 t/ha, superior as 6,0 t/ha, citadas por Denardin \& Kochhann (1993) e por Darolt (1998), como sendo a quantidade mínima ideal de adição de matéria seca em um sistema de rotação de culturas, de maneira que se mantenha adequada a cobertura do solo. Apenas as leguminosas em cultivo exclusivo não alcançaram a produtividade recomendada por esses autores. A baixa produtividade das leguminosas, principalmente da mucuna-preta, foi conseqüência da baixa produção de matéria fresca (Tabela 1). Contudo, Ferreira, A. (1996), Menezes et al. (2000) e Oliveira et al. (2000) obtiveram produtividade de matéria seca das leguminosas semelhante as da obtida no presente trabalho. 
Os valores obtidos superaram os rendimentos do sorgo em cultivo exclusivo e do consórcio milho e mucuna-preta (Salton, 1993), do consórcio do milho com as leguminosas (Nolla, 1999), do milheto em monocultivo (Calegari et al., 1993; Menezes et al., 2000; Oliveira et al., 2000) e consorciado com feijãode-porco e com mucuna-preta (Menezes et al., 2000).

A produção de matéria fresca do sorgo em cultivo exclusivo foi maior que a produção do consórcio desta espécie com as leguminosas, ao passo que em relação à matéria seca obtiveram-se rendimentos estatisticamente iguais. Por outro lado, Aita (1997) constatou que a produção de matéria seca do consórcio de gramíneas com leguminosas é superior à do cultivo isolado de cada espécie.

O milho em cultivo exclusivo apresentou produção de matéria fresca e matéria seca semelhante à produzida quando consorciado com as leguminosas. Por outro lado, os consórcios do milheto com as leguminosas produziram quantidade de matéria fresca semelhante ao cultivo isolado da gramínea. A produção de matéria seca do cultivo exclusivo foi estatisticamente semelhante à do consórcio com feijão-de-porco e maior com a mucuna-preta.

Quanto ao acúmulo médio de nutrientes nas plantas de cobertura, exceto para o $\mathrm{Ca}$, houve efeito significativo dos tratamentos sobre os outros nutrientes analisados (Tabela 2). Apenas a mucuna-preta apresentou baixo conteúdo de $\mathrm{N}$ acumulado, quando comparada aos demais tratamentos que, indepen- dente da forma de cultivo, acumularam quantidades superiores a $110 \mathrm{~kg} / \mathrm{h}$ a de nitrogênio.

$\mathrm{O}$ acúmulo de $\mathrm{P}$ foi superior nos cultivos exclusivos de milheto e sorgo, todavia não diferindo estatisticamente dos tratamentos de consórcio e do monocultivo de milho. Quanto ao conteúdo acumulado de $\mathrm{K}$, o consórcio milheto e mucuna-preta forneceu a maior quantidade ao solo por ocasião do manejo, possivelmente pela maior quantidade de matéria seca produzida neste tratamento (Tabela 1). O consórcio do milheto com feijão-de-porco e as gramíneas em cultivo exclusivo apresentaram acúmulos de $\mathrm{K}$ semelhantes aos deste tratamento.

As leguminosas em cultivo exclusivo apresentaram menor acúmulo de $\mathrm{K}$ e de $\mathrm{Mg}$, também relacionado ao baixo rendimento de matéria seca (Tabela 1). Obtiveram-se maiores valores para acúmulo de $\mathrm{S}$ nos tratamentos em que foi cultivado milheto, independentemente da forma de cultivo.

O conteúdo acumulado de $\mathrm{N}, \mathrm{P}$ e $\mathrm{K}$ foi inferior ao observado por Ceretta et al. (1994) no feijão-de-porco. Além disso, a quantidade de macronutrientes acumulada pela mucuna-preta e feijão-de-porco foi inferior à obtida por Alvarenga et al. (1995), à exceção do Ca, nesta última espécie, e do S, que não foi avaliado pelo autor. Aita (1997) relata resultados de diversos autores, em diferentes condições edafoclimáticas, em que o acúmulo de $\mathrm{N}$ é superior ao obtido neste trabalho. Contudo, as quantidades acumuladas de N, P e Mg estão dentro dos limites cita-

Tabela 1. Produtividade de matéria fresca, matéria seca e teor de matéria seca das plantas de cobertura em cultivo exclusivo e consorciado ${ }^{(1)}$.

\begin{tabular}{|c|c|c|c|}
\hline Plantas de cobertura & $\begin{array}{c}\text { Matéria fresca } \\
(\mathrm{t} / \mathrm{ha})\end{array}$ & $\begin{array}{c}\text { Teor de matéria seca } \\
(\%)\end{array}$ & $\begin{array}{c}\text { Matéria seca } \\
(\mathrm{t} / \mathrm{ha})\end{array}$ \\
\hline Milheto + mucuna-preta & $40,05 b c$ & $43,23 a$ & $17,01 \mathrm{a}$ \\
\hline Milheto + feijão-de-porco & $32,92 \mathrm{~cd}$ & $33,38 \mathrm{ab}$ & $10,81 \mathrm{ab}$ \\
\hline Sorgo + mucuna-preta & $47,50 \mathrm{bc}$ & $19,32 \mathrm{~d}$ & $9,21 \mathrm{~b}$ \\
\hline Sorgo + feijão-de-porco & $55,88 \mathrm{~b}$ & $23,02 \mathrm{~cd}$ & $11,18 \mathrm{ab}$ \\
\hline Milho + mucuna-preta & $43,75 b c$ & $28,44 b c$ & $12,42 \mathrm{ab}$ \\
\hline Milho + feijão-de-porco & $43,51 b c$ & $27,03 b c$ & $11,70 \mathrm{ab}$ \\
\hline Milheto & $45,76 \mathrm{bc}$ & $34,40 \mathrm{ab}$ & $14,18 \mathrm{ab}$ \\
\hline Sorgo & $77,19 a$ & $19,95 d$ & $15,48 \mathrm{ab}$ \\
\hline Milho & $45,79 b c$ & $26,83 b c$ & $12,17 \mathrm{ab}$ \\
\hline Mucuna-preta & $5,29 \mathrm{e}$ & $24,94 \mathrm{~cd}$ & $1,09 \mathrm{c}$ \\
\hline Feijão-de-porco & 13,96de & $24,61 \mathrm{~cd}$ & $3,43 \mathrm{c}$ \\
\hline Média & 41,05 & 27,00 & 10,02 \\
\hline $\mathrm{CV}(\%)$ & 21,00 & 3,59 & 12,25 \\
\hline
\end{tabular}

(1)Médias seguidas pela mesma letra, na coluna, não diferem entre si pelo teste de Tukey, a 5\% de probabilidade. 


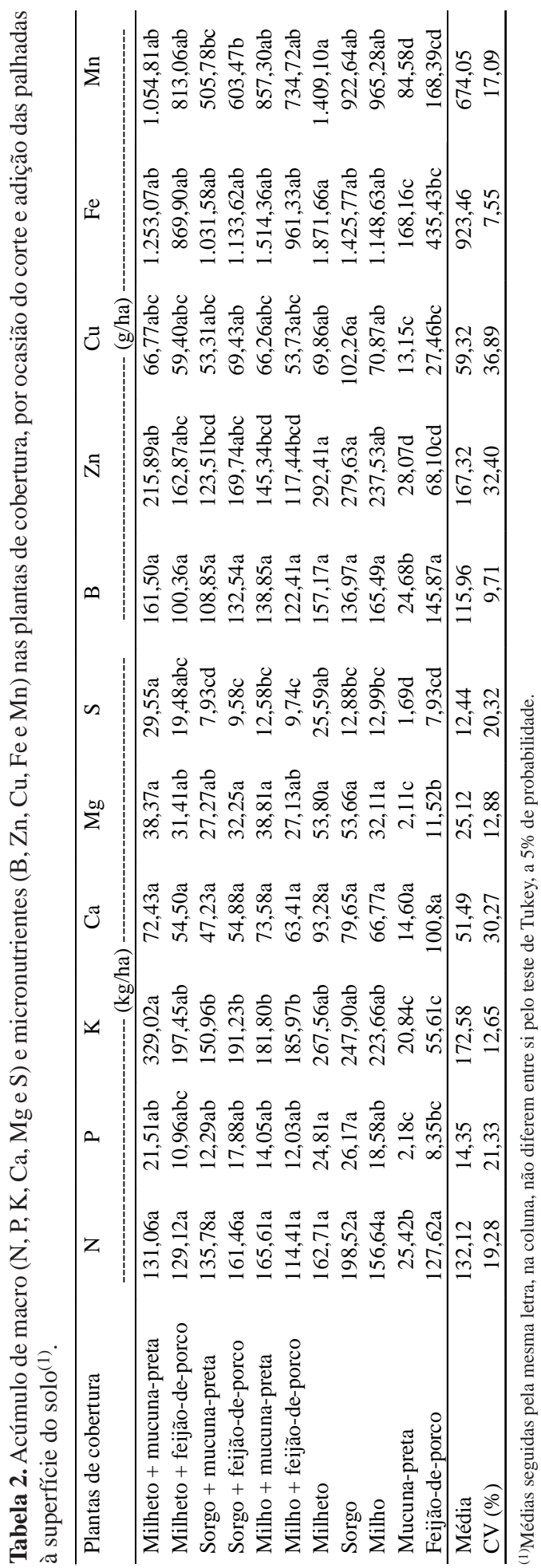

dos por Melarato (1999) para o feijão-de-porco. Quanto ao $\mathrm{K}$ e ao $\mathrm{Ca}$ foram encontrados valores superiores aos citados por esse autor. Em relação ao consórcio do milho com feijão-de-porco e com mucunapreta, Nolla (1999) constatou conteúdos acumulados de N, P, K, Ca e Mg, inferiores aos obtidos no presente trabalho, exceto com relação a $\mathrm{N}$ e $\mathrm{P}$ no consórcio com mucuna-preta.

De maneira geral, milheto e sorgo em cultivo exclusivo e o consórcio do milheto com a mucuna-preta destacaram-se como os tratamentos em que houve maior acúmulo de macronutrientes a serem fornecidos ao solo para o cultivo seguinte.

$\mathrm{O}$ acúmulo de $\mathrm{B}$ foi inferior apenas na mucunapreta em cultivo isolado, sendo as outras plantas de cobertura estatisticamente iguais com relação a este elemento. Quanto ao acúmulo dos demais micronutrientes, em geral o milheto e o sorgo em cultivo exclusivo apresentaram os maiores valores. As leguminosas em monocultivo apresentaram sempre acúmulos em quantidades inferiores.

$\mathrm{Na}$ segunda fase, houve diferença significativa entre os tratamentos, em relação às variáveis altura de plantas, peso de matéria seca da parte aérea, número de vagens por planta, peso médio de 100 grãos e rendimento de grãos (Tabela 3). Os valores encontrados foram superiores aos citados por Siqueira (1989), incluindo o número de grãos por vagem.

Com relação à altura de plantas, os feijoeiros cultivados sobre palhada de mucuna-preta e feijão-deporco, ambos em cultivo exclusivo, apresentaram as menores alturas quando comparadas às plantas dos demais tratamentos. É possível que nesses tratamentos, em virtude da decomposição mais rápida da palhada, tenha ocorrido maior evaporação direta da água retida no solo, em razão da elevação da temperatura, o que pode ter prejudicado o desenvolvimento das plantas. Conforme Bonde \& Willis (1969), citados por Balbino et al. (1996), quanto menor a quantidade de resíduos na superfície, maior a taxa de evaporação de água no solo ao longo do tempo. Portanto, pode-se supor que nos demais tratamentos, em que a produção de matéria seca foi maior (Tabela 1), tenha ocorrido maior proteção do solo, menor evaporação e, conseqüentemente, aumento da capacidade de armazenamento de água da chuva, que favoreceu o crescimento das plantas. 


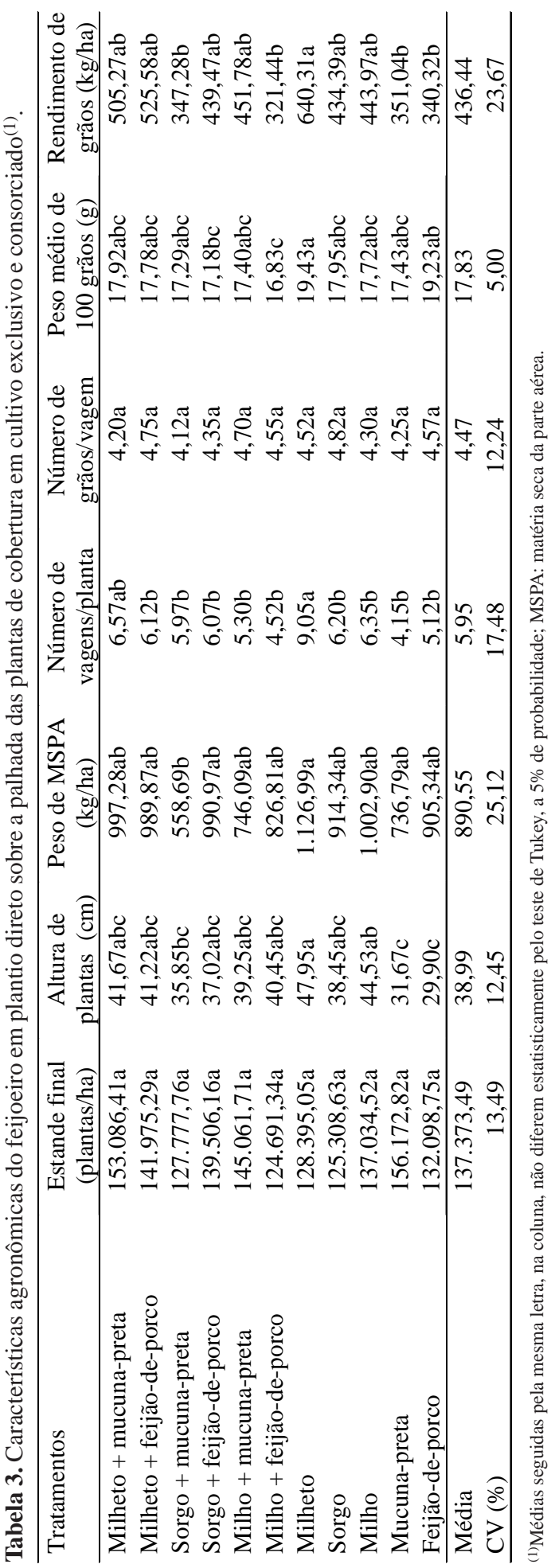

O maior peso de matéria seca da parte aérea foi obtido no tratamento com milheto em cultivo exclusivo e o menor sobre palhada de sorgo com mucunapreta.

Quanto ao número de vagens por planta, o melhor tratamento foi o do plantio do feijoeiro sobre palhada de milheto em cultivo exclusivo. Este resultado pode ser atribuído ao fato de o milheto ter produzido grande quantidade de matéria seca, proporcionando boa cobertura do solo, o que provavelmente manteve maior umidade do solo, propiciando formação de maior número de flores, e, conseqüentemente, de vagens.

Durante o período da floração, aproximadamente 45 dias após a germinação, houve a última chuva no local. Segundo O'Toole et al. (1977), citados por Portes (1996), o estresse hídrico reduz a fotossíntese, tornando escassa a disponibilidade de fotossintatos para o enchimento das vagens, podendo acarretarlhes a queda, fato que pode ter ocorrido nos demais tratamentos.

Quanto ao peso médio de 100 grãos, os melhores resultados foram obtidos pelas plantas cultivadas sobre as palhadas do feijão-de-porco e do milheto, ambos em cultivo exclusivo. Pode-se atribuir tal resultado ao fato de o feijão-de-porco ter disponibilizado o $\mathrm{N}$ em menor tempo que as demais plantas de cobertura, em razão de sua rápida decomposição (baixa relação C/N), segundo Calegari et al. (1993), Miyazawa et al. (1993) e Alvarenga et al. (1995).

Além disso, o maior acúmulo de $\mathrm{N}$ no feijoeiro ocorre entre 50 e 60 dias após a germinação, período de grande exigência em nutrientes para a produção de matéria fresca, formação de vagens e grãos (Oliveira et al., 1996). Segundo Resende et al. (2000), 60 dias é o prazo necessário para que ocorra mineralização de metade do $\mathrm{N}$ contido na parte aérea do feijão-de-porco. Assim, é provável que a disponibilização mais rápida do N, coincidindo com o período de exigência da cultura, tenha sido o fator que propiciou o melhor desenvolvimento das plantas e produção de grãos de maior tamanho pelo feijoeiro cultivado sobre a palhada desta leguminosa. Teixeira (1998) também observou que o aumento no peso médio de 100 grãos foi causado pelo aumento das doses de $\mathrm{N}$ utilizadas.

Já o milheto, com produção de matéria seca acima de $14 \mathrm{t} /$ ha (Tabela 1), possivelmente propiciou maior 
proteção ao solo e maior retenção de umidade, diminuindo o déficit hídrico e favorecendo a formação de grãos. Voss \& Sidiras, citados por Balbino et al. (1996), também constataram que a maior conservação da água e a menor variação de temperatura no solo foram os principais fatores responsáveis pelo aumento de produtividade no plantio direto do feijoeiro. Além disso, o milheto em cultivo exclusivo apresentou o maior acúmulo de macronutrientes a ser fornecido ao cultivo seguinte pela decomposição da palhada (Tabela 2). Embora o tratamento de milheto consorciado com mucuna-preta também tenha apresentado tais vantagens, não se observou efeito positivo com relação ao peso médio de 100 grãos.

Os maiores rendimentos de grãos foram obtidos nos tratamentos com milheto, especialmente no cultivo exclusivo (Tabela 3). É possível que a elevada quantidade de matéria seca produzida, com elevado acúmulo de macro e micronutrientes apresentado por estes tratamentos (Tabela 2), e a alta relação $\mathrm{C} / \mathrm{N}$ do milheto (Calegari et al., 1993), possibilitando maior tempo de permanência da palhada na superfície do solo, tenham contribuído para o maior rendimento de grãos.

A média geral de produtividade do experimento foi de $436 \mathrm{~kg} / \mathrm{ha}$, a qual encontra-se abaixo dos valores obtidos por Silva (1994), Teixeira (1998) e Valério (1998). O fator responsável para essa diferença deve estar relacionado ao estande superior e à irrigação utilizada por esses autores em seus estudos. Embora a produtividade média observada seja baixa, ela está de acordo com o encontrado por Santos \& Braga (1998). Além disso, o feijoeiro apresenta baixa produtividade na safra da seca (Vieira, 1967; Fontes, 1972; Batista et al., 1975; Chaib et al., 1984), a qual estaria relacionada com a pequena quantidade de água disponível no solo, levando ao menor crescimento do sistema radicular e restringindo, conseqüentemente, a absorção e translocação de nutrientes (Moraes, 1988).

\section{Conclusões}

1. O sorgo em monocultivo apresenta maior produtividade de matéria fresca.

2. O consórcio milheto com mucuna-preta apresenta maior produtividade de matéria seca.
3. Milheto e sorgo em cultivo exclusivo, e o consórcio de milheto com mucuna-preta, acumulam maior quantidade de nutrientes na palhada.

4. O rendimento de grãos da cultura do feijoeiro no sistema de plantio direto é influenciado pelas diferentes palhadas das plantas de cobertura, sendo mais afetado pela espécie produtora de palha que pela sua forma de cultivo.

\section{Referências}

AITA, C. Dinâmica do nitrogênio no solo durante a decomposição de plantas de cobertura: efeito sobre a disponibilidade de nitrogênio para a cultura em sucessão. In: FRIES, M. R.; DALMOLIN, R. S. D. (Coord.). Atualização em recomendação de adubação e calagem: ênfase em plantio direto. Santa Maria: UFSM/Pallotti, 1997. p. 76-111. Palestras apresentadas no III curso.

AlCÂntara, P. B.; BUfARAH, G. Plantas forrageiras: gramíneas e leguminosas. 5. ed. São Paulo: Nobel, 1988. 162 p.

ALVARENGA, R. C.; COSTA, L. M. da; MOURA FILHO, W.; REGAZZI, A. J. Características de alguns adubos verdes de interesse para a conservação e recuperação de solos. Pesquisa Agropecuária Brasileira, Brasília, v. 30, n. 2, p. 175-185, fev. 1995.

ASSOCIAÇÃO BRASILEIRA DE EDUCAÇÃ̃ AGRÍCOLA SUPERIOR (Brasília, DF). Secagem de sementes. Brasília, 1987. 37 p.

BALBINO, L. C.; MOREIRA, J. A. A.; SILVA, J. G. da; OLIVEIRA, E. F. de; OLIVEIRA, I. P. de. Plantio direto. In: ARAUJO, R. S.; RAVA, C. A.; STONE, L. F.; ZIMMERMANN, M. J. de O. (Coord.). Cultura do feijoeiro comum no Brasil. Piracicaba: Potafos, 1996. p. 301-352.

BANZATTO, D. A.; KRONKA, S. N. Experimentação agrícola. 3. ed. Jaboticabal: Funep, 1995. 247 p.

BATISTA, C. D.; BRUNE, W.; BRAGA, J. M. Efeito da população de plantas e da época de plantio no crescimento do feijoeiro (Phaseolus vulgaris L.). V. Absorção de micronutrientes. Experientiae, Viçosa, MG, v. 19, n. 3, p. 33-57, fev. 1975.

CALEGARI, A. Leguminosas para adubação verde de verão no Paraná. Londrina: Iapar, 1995. 118 p. (Circular, 80). 
CALEGARI, A.; MONDARDO, A.; BULISANI, E. A.; COSTA, M. B. B. da; MIYASAKA, S.; AMADO, T. J. C. Aspectos gerais da adubação verde. In: COSTA, M. B. B. da (Coord.). Adubação verde no sul do Brasil. 2. ed. Rio de Janeiro: Assessoria e Serviços a Projetos em Agricultura Alternativa, 1993. p. 1-56.

CERETTA, C. A.; AITA, C.; BRAIDA, J. A.; PAVINATO, A.; SALET, R. L. Fornecimento de nitrogênio por leguminosas na primavera para o milho em sucessão nos sistemas de cultivo mínimo e convencional. Revista Brasileira de Ciência do Solo, Campinas, v. 18, n. 2, p. 215-220, maio/ago. 1994.

CHAIB, S. L.; BULIZANI, E. A.; CASTRO, L. H. S. M. de. Crescimento e produção do feijoeiro em resposta a profundidade de aplicações de adubo fosfatado. Pesquisa Agropecuária Brasileira, Brasília, v. 19, n. 7, p. 817-822, jul. 1984.

COMISSÃO DE FERTILIDADE DO SOLO DO ESTADO DE MINAS GERAIS (Lavras, MG). Recomendação para o uso de corretivos e fertilizantes em Minas Gerais: 4⿳亠口冋 aproximação. Lavras, 1989. 176 p.

DAROLT, M. R. Princípios para implantação e manutenção do sistema. In: DAROLT, M. R. Plantio direto: pequena propriedade sustentável. Londrina: Iapar, 1998. p. 16-45 (Circular, 101).

DENARDIN, J. E.; KOCHHANN, R. A. Requisitos para a implantação e a manutenção do sistema plantio direto. In: EMBRAPA. Centro Nacional de Pesquisa de Trigo (Passo Fundo, RS). Plantio direto no Brasil. Passo Fundo: Embrapa-CNPT/Fecotrigo/Fundação ABC/Aldeia Norte, 1993. p. 19-27.

FERREIRA, A. M. Efeito de adubos verdes nos componentes de produção de diferentes cultivares de milho. 1996. 70 f. Dissertação (Mestrado em Fitotecnia) - Universidade Federal de Lavras, Lavras.

FERREIRA, P. V. Estatística experimental aplicada à agronomia. 2. ed. Maceió: Edufal, 1996. 606 p.

FONTES, L. A. N. Nota sobre os efeitos da aplicação de adubo nitrogenado e fosfatado, calcário e inoculante na cultura do feijão (Phaseolus vulgaris L.). Revista Ceres, Viçosa, MG, v. 19, n. 103, p. 211-216, 1972.

MELARATO, M. Manejo da fertilidade do solo em culturas perenes sob plantio direto. Revista Plantio Direto, Passo Fundo, n. 52, p. 15-23, jul./ago. 1999.

MENEZES, L. A.; LEANDRO, W. M.; PIRES JÚNIOR, V. T.; LIMA, J. E. S.; CARVALHO, G. S. de; BOTELHO,
S. A. Biomassa total e residual de coberturas, com potencial de utilização em plantio direto, isoladas ou consorciadas com gramíneas, plantadas em safrinha em Goiás. In: REUNIÃO BRASILEIRA DE MANEJO E CONSERVAÇÃO DO SOLO E DA ÁGUA, 13., 2000, Ilhéus. Anais... Ilhéus: Ceplac/Sociedade Brasileira de Ciência do Solo, 2000. 1 CD-ROM.

MIYAZAWA, M.; PAVAN, M. A.; CALEGARI, A. Efeito de material vegetal na acidez do solo. Revista Brasileira de Ciência do Solo, Campinas, v. 17, n. 3, p. 411416, set./dez. 1993.

MORAES, J. F. V. Calagem e adubação. In: ZIMMERMANN, M. J. de O.; ROCHA, M.; YAMADA, T. (Ed.). Cultura do feijoeiro: fatores que afetam a produtividade. Piracicaba: Potafos, 1988. p. 261262.

NOLLA, A. Avaliação do consórcio milho leguminosas para adubação verde e plantas espontâneas. 1999. 123 f. Dissertação (Mestrado em Solos e Nutrição de Plantas) Universidade Federal de Viçosa, Viçosa.

OLIVEIRA, H. C. de; LEANDRO, W. M.; OLIVEIRA JÚNIOR, J. P. de; LIMA, J. H. S.; BOTELHO, S. A. Biomassa total de coberturas verdes plantadas no verão em sistema de plantio direto em Goiás. In: REUNIÃO BRASILEIRA DE MANEJO E CONSERVAÇÃO DO SOLO E DA ÁGUA, 13., 2000, Ilhéus. Anais... Ilhéus: Ceplac/Sociedade Brasileira de Ciência do Solo, 2000. 1 CDROM.

OLIVEIRA, I. P. de; ARAUJO, R. S.; DUTRA, L. G. Nutrição mineral e fixação biológica de nitrogênio. In: ARAUJO, R. S.; RAVA, C. A.; STONE, L. F.; ZIMMERMANN, M. J. de O. (Coord.). Cultura do feijoeiro comum no Brasil. Piracicaba: Potafos, 1996. p. $169-222$.

PORTES, T. de A. Ecofisiologia. In: ARAUJO, R. S.; RAVA, C. A.; STONE, L. F.; ZIMMERMANN, M. J. de O. (Coord.). Cultura do feijoeiro comum no Brasil. Piracicaba: Potafos, 1996. p. 101-138.

RESENDE, A. S. de; QUESADA, D. M.; XAVIER, R. P.; BODDEY, R. M.; GUERRA, J. G. M.; ALVES, B. J. R.; URQUIAGA, S. Taxa de decomposição de talos e folhas de três leguminosas utilizadas para fins de adubação verde. In: REUNIÃO BRASILEIRA DE MANEJO E CONSERVAÇÃO DO SOLO E DA ÁGUA, 13., 2000, Ilhéus. Anais... Ilhéus: Ceplac/Sociedade Brasileira de Ciência do Solo, 2000. 1 CD-ROM.

SALTON, J. C. Alternativas para produzir palha no Mato Grosso do Sul. In: EMBRAPA. Centro Nacional de Pes- 
quisa de Trigo (Passo Fundo, RS). Plantio direto no Brasil. Passo Fundo: Embrapa-CNPT/Fecotrigo/Fundação ABC/Aldeia Norte, 1993. p. 159-162.

SANTOS, M. L.; BRAGA, M. J. Aspectos econômicos. In: VIEIRA, C.; PAULA JÚNIOR, T. J.; BORÉM, A. (Ed.). Feijão: aspectos gerais e cultura no Estado de Minas Gerais. Viçosa, MG: UFV, 1998. p. 19-53.

SILVA, V. A. da. Efeitos de métodos de preparo do solo e níveis de fertilizante NPK sobre o feijão da "seca" (Phaseolus vulgaris L.) em seqüência à cultura do milho (Zea mays L.). 1994. 66 f. Dissertação (Mestrado em Fitotecnia) - Universidade Federal de Lavras, Lavras.

SIQUEIRA, N. S. Efeitos de sistemas de preparo do solo sobre a cultura do feijoeiro e sobre algumas propriedades físicas e químicas do solo. 1989. 106 f. Dis- sertação (Mestrado em Fitotecnia) - Universidade Federal de Viçosa, Viçosa.

TEIXEIRA, I. R. Comportamento do feijoeiro (Phaseolus vulgaris L. cv. Pérola) submetido a diferentes densidades de semeadura e níveis de adubação nitrogenada. 1998. 67 f. Dissertação (Mestrado em Fitotecnia) - Universidade Federal de Lavras, Lavras.

VALÉRIO, C. R. Comportamento de cultivares de feijão tipo carioca em diferentes populações de plantas e espaçamentos entre linhas. 1998. 69 f. Dissertação (Mestrado em Fitotecnia) - Universidade Federal de Lavras, Lavras.

VIANELLO, R. L.; ALVES, A. R. Meteorologia básica e aplicações. Viçosa, MG: UFV, 1991. 449 p.

VIEIRA, C. O feijoeiro comum: cultura, doenças e melhoramento. Viçosa, MG: UFV, 1967. 220 p. 